\title{
CONFLICTOS INTERPRETATIVOS EN TORNO AL DESCANSO SEMANAL
}

\author{
Raquel Poquet Catalá \\ Profesora Asociada \\ Universidad de Valencia
}

\begin{abstract}
En este trabajo se analiza el régimen jurídico del descanso semanal, desde su marco normativo, su fundamentación teórica y jurídica, y los conflictos planteados alrededor del mismo, especialmente, su posible solapamiento o acumulación con el descanso diario; la concreción del día de disfrute, sea éste el domingo u otro día semanal y su rigidez; y la acumulación por períodos de hasta tres días cuando se presta servicios durante once días.

In this work it is analyzed the legal regime of weekly rest, from its normative framework, its theoretical and legal foundation, and the conflicts raised around it, especially, its possible overlap or accumulation with daily rest; the realization of the day of enjoyment, be it Sunday or another weekly day and its rigidity; and accumulation for periods of up to three days when services are provided for eleven days.
\end{abstract}

Title: Interpretative conflicts about the weekly rest

Palabras clave: descanso semanal, descanso diario, acumulación, persona trabajadora. Key words: weekly rest, daily rest, accumulation, worker.

IUSLabor 3/2020, ISSN 1699-2938, p. 123-147.

DOI. 10.31009/IUSLabor.2020.i03.05

Fecha envío: 07.07.2020 | Fecha aceptación: 28.09.2020 


\section{Sumario}

1. Introducción.

2. Fundamento.

3. Acumulación con el descanso diario.

4. Concreción del día de disfrute.

4.1. Aspectos generales.

4.2.Descanso semanal, domingo y religión católica.

4.3.Descanso semanal, domingo y conciliación de la vida laboral y familiar.

5. Acumulación del descanso semanal por períodos de hasta catorce días.

5.1.La ordenación del descanso semanal según la norma estatutaria.

5.2.La ordenación del descanso semanal en la negociación colectiva.

6. Bibliografía. 


\section{Introducción}

El derecho a un descanso semanal retribuido constituye uno de los derechos básicos de toda persona trabajadora. Así, desde la perspectiva internacional, queda recogido en el artículo 24 Declaración Universal de Derechos Humanos ${ }^{1}$ que señala que "toda persona tiene derecho al descanso, al disfrute del tiempo libre, a una limitación razonable de la duración del trabajo y a vacaciones periódicas pagadas"; en el artículo 7 Pacto Internacional de Derechos Económicos, Sociales y Culturales ${ }^{2}$ que expresa que "los Estados partes en el presente pacto reconocen el derecho de toda persona al goce de condiciones de trabajo equitativas y satisfactorias que le aseguren en especial (...) d) El descanso, el disfrute del tiempo libre, la limitación razonable de las horas de trabajo y las vacaciones periódicas pagadas, así como la remuneración de los días festivos"; o el Convenio núm. 14 OIT $^{3}$ cuyo artículo 2 establece que "todo el personal empleado en cualquier empresa industrial, pública o privada, o en sus dependencias, deberá disfrutar, en el curso de cada período de siete días, de un descanso que comprenda como mínimo veinticuatro horas consecutivas... que coincidirá, siempre que sea posible, con los días consagrados por la tradición o las costumbres del país o de la región a las personas empleadas en empresas industriales en las que únicamente estén empleados los miembros de una misma familia"; el Convenio núm. $106 \mathrm{OIT}^{4}$; el Convenio núm. $132 \mathrm{OIT}^{5}$; o el Convenio núm. $146 \mathrm{OIT}^{6}$.

En el ámbito comunitario queda también recogido en el artículo 2 de la Carta Social Europea $^{7}$; en el artículo 31 de la Carta de los Derechos Fundamentales de la Unión Europea ${ }^{8}$, que establece que "todo trabajador tiene derecho a la limitación de la duración máxima del trabajo y a períodos de descanso diarios y semanales, así como a un período de vacaciones anuales retribuidas"; y en la Directiva 2003/88/CE ${ }^{9}$. Los objetivos de esta Directiva son, básicamente, paliar las consecuencias negativas que el tiempo de trabajo tiene sobre la seguridad y salud; buscar vías para encontrar un equilibrio entre la seguridad y salud de las personas trabajadoras; y la ordenación flexible del tiempo de trabajo.

\footnotetext{
${ }^{1}$ De 10 de diciembre de 1948.

${ }^{2}$ De 16 de diciembre de 1966.

${ }^{3}$ De 25 de octubre de 1921, sobre el descanso semanal (industria)

${ }^{4}$ De 5 de junio de 1957, sobre el descanso semanal (comercio y oficinas)

${ }^{5}$ De 3 de junio de 1970, sobre vacaciones pagadas (revisado).

${ }^{6}$ De 13 de octubre de 1976, sobre vacaciones pagadas de la gente del mar.

${ }^{7}$ De 18 de octubre de 1961.

${ }^{8}$ De 7 de diciembre de 2000.

${ }^{9}$ De 4 de noviembre, relativa a determinados aspectos de la ordenación del tiempo de trabajo.
} 
En el ámbito interno, es el artículo 40.2 CE, bajo la rúbrica "De los principios rectores de la política social y económica" el que ordena que los poderes públicos "garantizarán el descanso necesario, mediante la limitación de la jornada de trabajo". Este mandato constitucional dirigido a los poderes públicos contiene la base fundamental sobre la cual nuestra norma fundamental erige la atención sobre el derecho a un descanso necesario. No cabe duda de que en el ámbito laboral el descanso de los trabajadores requiere de un marco en el cual la presencia de la norma estatal resulta imprescindible, sin que puedan ser atendidas eventuales pretensiones de libertad para la autonomía individual o colectiva en aras a conseguir otro marco de regulación alejado de mandatos imperativos que tiendan a cubrir de otro modo la garantía del derecho afectado ${ }^{10}$.

Ya con anterioridad, la Ley de 12 de julio de 1940 reguló el denominado descanso dominical, siendo en $1976^{11}$ cuando se permite por disposición expresa en contrato o por autorización del Ministerio de Trabajo un régimen de descanso semanal diferente al establecido con carácter general, añadiendo asimismo medio día más al descanso semanal. Esta fórmula es repetida posteriormente con el ET de $1980^{12}$. El actual ET establece en su artículo 37.1 que "los trabajadores tendrán derecho a un descanso mínimo semanal, acumulable por períodos de hasta catorce días, de día y medio ininterrumpido que, como regla general, comprenderá la tarde del sábado o, en su caso, la mañana del lunes y el día completo del domingo". A continuación, permite que el gobierno establezca ampliaciones o limitaciones en la jornada, así como la fijación de regímenes de descanso alternativos para actividades concretas. Dicho precepto es desarrollado por el RD 1561/1995 ${ }^{13}$, de jornadas especiales, el cual, por ejemplo, en relación con las actividades de comercio, permite que mediante convenio colectivo o por acuerdo entre la empresa y los representantes legales de los trabajadores podrá acumularse el medio día de descanso semanal por períodos de hasta cuatro semanas, o su separación respecto del día completo para su disfrute en otro día de la semana ${ }^{14}$. Este descanso constituye claramente un derecho mínimo e indisponible, siendo ininterrumpible y sin posibilidad de fraccionamiento, aunque flexible en la medida en que el medio día se puede disfrutar el sábado o el lunes, o acumularlo por períodos de catorce

\footnotetext{
${ }^{10}$ Ramos QuintanA, Margarita Isabel, "Los descansos laborales”, en AA.VV., Tiempo de trabajo. Albacete, Bomarzo, 2007, p. 121

${ }^{11}$ Ley de 8 de abril de 1976, de relaciones laborales. Literalmente, establecía en su artículo 25: "El trabajador tendrá derecho a un descanso semanal mínimo de día y medio ininterrumpido que, como regla general, comprenderá la tarde del sábado o la mañana del lunes y el día completo del domingo, salvo disposición legal expresa o autorización del Ministerio de Trabajo, previo informe de la Organización Sindical, que permita otro régimen de descanso laboral para determinadas actividades o Empresas concretas, teniendo en cuenta sus necesidades y los intereses de las partes afectadas".

${ }^{12}$ Ley 8/1980, de 10 de marzo.

${ }^{13}$ De 21 de septiembre.

${ }^{14}$ Artículo 6 RD 1561/1995.
} 
días. Como señala la doctrina judicial ${ }^{15}$, las características del descanso semanal se sintetizan en que "es mínimo e irrenunciable, pudiendo ser sólo mejorado por convenio colectivo o contrato; que es ininterrumpido, sin posibilidad de fraccionamiento; que es flexible, el medio día de descanso se puede disfrutar el sábado o el lunes; que es acumulable el descanso correspondiente a cada semana por períodos de hasta catorce días".

\section{Fundamento}

No cabe duda de que el fundamento de la regulación de un descanso semanal tiene su razón de ser en la necesidad de garantizar un período de recuperación físico, psíquico y social de toda persona trabajadora. Se trata de preservar, en el fondo, los bienes jurídicos de descanso necesario y de libre desarrollo de la personalidad. Es decir, de garantizar la recuperación del estado de salud -a todos su niveles-, de garantizar un período de ocio y de esparcimiento a la persona trabajadora, esto es, la capacidad de "autodeterminación consciente y responsable de la propia vida"16.

En palabras de la doctrina, tiene como finalidad "garantizar al trabajador periódicamente el disfrute de un tiempo de desvinculación del trabajo suficientemente amplio que posibilite, no sólo el descanso y la recuperación del desgaste experimentado durante el transcurso de cada semana laborable, sino también la atención de sus necesidades, intereses y responsabilidades de carácter personal y familiar" ${ }^{" 17}$.

La configuración de los conceptos de tiempo de trabajo y tiempo de descanso tienen su base en la Directiva 2003/88/CE, que en su artículo 2 considera como tiempo de trabajo todo período durante el cual el trabajador permanezca en el trabajo, a disposición del empresario y en el ejercicio de su actividad o de sus funciones, añadiendo a continuación que el período de descanso es todo aquél que no es tiempo de trabajo.

Así, el artículo 37.1 ET configura un descanso de periodicidad semanal, concretamente, de un día y medio ininterrumpido a la semana -y dos días para los menores de edad-, con carácter general, configurándose, además, esta norma como de derecho necesario, por lo que por vía convencional o contractual puede establecerse una duración mayor del descanso. El ET es, en este sentido, más beneficioso que la citada Directiva comunitaria, la cual encomienda a los Estados miembros a garantizar un descanso mínimo de 24 horas ininterrumpidas por cada período de siete días.

\footnotetext{
${ }^{15}$ STSJ Baleares, de 31 de marzo de 2014, rec. núm. 4/2014.

${ }^{16}$ SSTC 53/1985, de 11 de abril; 192/2003, de 27 de octubre; 324/2006, de 20 de noviembre.

${ }^{17}$ Molero Manglano, Carlos, (Coord.), Manual de Derecho del Trabajo. Valencia, Tirant lo Blanch, 2015 (versión on line)
} 
No obstante, el RD 1561/1995 recoge algunas particularidades para determinados sectores productivos, como el colectivo de la minería que prevé un descanso semanal de dos días para aquellos trabajadores que presten sus servicios en puestos de trabajo subterráneo o en el exterior, pero cuya actividad sólo pueda producirse simultáneamente a la de los primeros.

Como características de su configuración, debe destacarse su automaticidad, puesto que el descanso semanal interrumpe la prestación laboral según un ritmo que viene establecido de forma rígida. En segundo lugar, tiene un carácter retribuido, aspecto que la doctrina ${ }^{18}$ ha calificado como inherente a la noción de descanso semanal, pues así se deduce del artículo 26.1 ET que considera salario a los períodos de descanso computables como de trabajo.

\section{Acumulación con el descanso diario}

Uno de los aspectos más debatidos en relación al descanso semanal es su relación con el descanso diario o inter-jornadas, pues según la interpretación que se realice, su duración será diferente. Es decir, en función de si se entienda que el descanso diario es independiente del semanal, o que éste absorbe al primero, la duración y el régimen jurídico es totalmente diferente.

Esta íntima conexión, tanto teleológica como temporal, entre el descanso semanal y el diario ha llevado a la doctrina judicial ${ }^{19}$ y jurisprudencia ${ }^{20}$ a dictaminar en este punto que

\footnotetext{
${ }^{18}$ Alonso Olea, Manuel; Casas BaAmonde, Ma Emilia, Derecho del Trabajo, Madrid, Civitas, 2001, p. 408.

${ }^{19}$ SSAN de 7 de mayo de 2007, st. núm. 44/2007, recogiendo la STS de 20 de diciembre de 2002, rec. núm. 148/2001; de 24 de octubre de 2006, proc. núm. 127/2006; SSTSJ Castilla y León, de 9 de noviembre de 2011, rec. núm. 1594/2011; País Vasco, de 1 de junio de 2011, rec. núm. 805/2011; Canarias, de 28 de febrero de 2011, rec. núm. 25/2009; Madrid, de 14 de octubre de 2010, rec. núm. 506/2010.

${ }^{20}$ STS de 5 de octubre de 2010, rec. núm. 25/2009, que enjuicia un caso donde la empresa pretendía omitir el descanso del medio día adicional al del día entero de descanso, mediante el artificio de hacer el cómputo por horas del día y medio día de descanso semanales, de modo que descansando la noche del sábado y el domingo habría que entrar a trabajar en la mañana del lunes, pues desde el fin de la jornada del sábado hasta el inicio de la mañana del lunes habrían transcurrido 36 horas. La primera sentencia del TS al respecto fue de 5 de septiembre de 2008, rec. núm. 109/2007 (caso Leroy Merlin), criterio que fue fijado por sus posteriores sentencias de 25 de septiembre de 2008, rec. núm. 109/2007 (caso Carrefour); de 23 de octubre de 2008, rec. núm. 157/2006 (caso Makro Autoservicios de mayorista); de 27 de noviembre de 2008, rec. núm. 1949/2008 (caso Alcampo). En todas ellas se enjuicia el artículo 32.10 del Convenio Colectivo de Grandes Almacenes que establece que "el cumplimiento del artículo 37 de la Ley del Estatuto de los Trabajadores, y el Real Decreto 1561/1995, en lo que se refiere al descanso semanal, podrá ser compensado mediante el disfrute de un día de descanso a la semana. En este último caso, se entenderá en
} 
el descanso semanal de día y medio no es lo mismo que "treinta y seis" horas, pues el concepto de "día y medio" ininterrumpido a que se refiere el artículo 37.1 equivale al disfrute de un descanso de "treinta y seis horas" consecutivas. Pero en el sentido de que, si al trabajador le coincide el día de descanso semanal en domingo, ha de descansar también la tarde del sábado o la mañana del lunes y, si no coincide en domingo, el descanso semanal incluirá el día correspondiente y la tarde del antecedente o mañana del día siguiente. De esta forma, lo que se trata es de evitar que el tiempo que queda tras realizar una jornada completa se solape con el correspondiente al descanso semanal del trabajador, pues se trata de determinar si constituyen descansos con autonomía propia, o por el contrario, son períodos de reposo indisolublemente relacionados, es decir, precisar si cuando el trabajador finaliza su jornada, con independencia de la hora en que ello se produzca, el resto del día se computará como descanso diario y no como medio día de descanso semanal, o bien si el tiempo que transcurre desde el final de la jornada supone el inicio del descanso semanal, esto es, tiempo a cuenta del medio día de asueto.

La doctrina judicial ${ }^{21}$ sostiene que la propuesta de cómputo de los descansos diario y semanal no aumenta, ni disminuye el tiempo de descanso de los trabajadores, y tampoco repercute en la duración de la jornada anual pactada en convenio colectivo. Es decir, considera que los descansos diario y semanal tienen plena autonomía, de manera que la aplicación de uno de ellos no viene condicionada por la del otro, puesto que como se trata de descansos mínimos, dichos descansos no son acumulables, ni tienen que disfrutarse de forma consecutiva, porque dicho efecto jurídico no se deduce expresamente de los artículos 34.3.1 y 37.1 ET. Desde esta perspectiva, el descanso semanal puede comenzar al finalizar la jornada de sábado, ya que lo realmente importante es que al final de la jornada semanal el trabajador disfrute las doce horas de descanso diario y el día y medio de descanso semanal. No se debe tener presente únicamente el aspecto cuantitativo de la jornada, sino también el cualitativo, y es precisamente esta última idea la que permite

turnos rotativos a lo largo de toda la semana y no será posible su compensación económica. De mutuo acuerdo entre empresas y trabajadores podrá acumularse el medio día de descanso semanal para su disfrute en otro momento dentro de un ciclo no superior a cuatro semanas, y el día completo de descanso dentro de un ciclo no superior a catorce días, así como la recuperación del disfrute por la coincidencia del día libre rotativo con festivo, sin que ello implique reducción de la jornada anual pactada en el Convenio Colectivo...". El actual convenio colectivo de Grandes Almacenes, Resol. de 8 de abril de 2013, establece en su artículo 27.2 “de la jornada anual contratada, de conformidad con lo dispuesto en el artículo 34.2 del Estatuto de los Trabajadores, y una vez ya distribuida, se podrá disponer del porcentaje de horas previsto legalmente. La distribución de tales horas deberá respetar los períodos mínimos de descanso diario y semanal previstos en la Ley, dando conocimiento al trabajador con un preaviso mínimo de siete días, del día y la hora de la prestación de trabajo. A los presentes efectos, la disposición por parte de la empresa de este tiempo de trabajo se producirá, bien sin previsión de tal número de horas, o bien modificando en igual número las horas planificadas, siempre con el preaviso previsto en el párrafo anterior".

${ }^{21}$ SAN de 19 de noviembre de 2008, proc. núm. 141/2008. 
deducir que los descansos diarios y semanales no se pueden superponer.

Uno de los argumentos interpretativos a favor de la conexión de los descansos diario y semanal se contiene en el artículo 5 Directiva 2003/88/CE ${ }^{22}$, que presupone la necesidad de sumar de forma consecutiva los descansos. De este modo, se disfrutaría, en primer lugar, el descanso diario y posteriormente el semanal. Dichos descansos deberán, pues, disfrutarse de forma consecutiva, de manera que el descanso semanal se concederá de manera subsiguiente o posterior al descanso entre jornadas, puesto que prevalece en este último descanso la finalidad recuperadora de la jornada inmediatamente anterior. La normativa comunitaria prevé que el descanso diario se debe disfrutar la jornada anterior al período de descanso semanal, de suerte que ambos descansos no se pueden superponer entre sí. Se tendrá, pues, que permitir mediante el reposo diario la recuperación del trabajador y se iniciará el disfrute del descanso semanal el día siguiente a la última jornada de trabajo de la semana ${ }^{23}$. Asimismo, se justifica esta tesis en base a la interpretación histórica del 37.1 ET, ya que su anterior versión, contenida con el mismo numeral en la LRL de 1976, sustituyó la redacción original manejada en la tramitación parlamentaria, que hacía referencia a las treinta y seis horas de descanso, en vez de al día y medio de descanso. Finalmente, la redacción de la LRL acogió la expresión día y medio de descanso, ya que ello no suponía una mejora de la duración del asueto. Por último, la imposibilidad de superposición de los descansos diario y semanal se infiere directamente de la regulación del ET, de tal forma que no se podrán neutralizar las horas de asueto mediante el cómputo de las doce horas de descanso diario dentro del día y medio de reposo semanal ${ }^{24}$. El régimen jurídico diferente de cada período de descanso permite limitar las posibilidades de distribución irregular de la jornada de trabajo a lo largo del año. El artículo 34.2, in fine, del ET prevé la necesidad de "respetar en todo caso los períodos mínimos de descanso diario y semanal" contemplados en la legislación laboral a la hora de realizar la ordenación del tiempo de trabajo, de tal forma que se puede decir que el carácter necesario del descanso supone una limitación de los poderes de organización del trabajo de la empresa frente a los márgenes de distribución irregular de la jornada laboral. De hecho, según nuestra legislación nacional, cabe inferir el carácter independiente y autónomo de los descansos diario y semanal, pues, aunque comparten

\footnotetext{
${ }^{22}$ Literalmente, el artículo indicado prevé que "Los Estados miembros adoptarán las medidas necesarias para que todos los trabajadores disfruten, por cada período de siete días, de un período mínimo de descanso ininterrumpido de veinticuatro horas, a las que se añadirán las once horas de descanso diario establecidas en el artículo 3".

${ }^{23}$ SSTSJ País Vasco, de 1 de junio de 2011, rec. núm. 805/2011; Madrid, de 14 de octubre de 2010, rec. núm. 506/2010; Extremadura, de 12 de noviembre de 1992; Andalucía, de 27 de julio de 1990.

${ }^{24}$ SSTS de 23 de octubre de 2008, rec. núm. 151/2006; de 25 de septiembre de 2008, rec. núm. 109/2007; de 5 de septiembre de 2008, rec. núm. 109/2007; de 10 de octubre de 2005, rec. núm. 155/2004; SSAN de 6 de julio de 2004, st. núm. 64/2004; de 21 de junio de 2003; STSJ Canarias, de 29 de septiembre de 2006, rec. núm. 900/2005.
} 
una misma naturaleza jurídica y finalidad, no obstante, tienen régimen jurídico diverso, ya que uno tiene una periodicidad diaria, y otro semanal. En este sentido, se puede decir que el carácter necesario del descanso supone una limitación de los poderes de organización del trabajo de la empresa frente a los márgenes de distribución irregular de la jornada laboral ${ }^{25}$. De este modo, el legislador ordinario restringe las posibilidades de gestión empresarial del descanso diario a diferencia de lo que sucede en el descanso semanal, cuyo disfrute se puede distribuir con mayor margen de libertad. Y, en este sentido, es preciso decir que en nuestro ordenamiento jurídico el carácter necesario y obligatorio del descanso diario y semanal, se refuerza en virtud de la calificación del incumplimiento de dichos descansos como infracción laboral grave.

En síntesis, no cabe duda de que, en caso de solapamiento, se producirá la omisión del medio día de descanso semanal o bien la merma de determinadas horas correspondientes al descanso entre jornadas. Y este efecto no se puede justificar en el hecho de que el descanso semanal se compute por horas, de modo que descansando la noche del sábado y el día completo del domingo se deba entrar a trabajar la mañana del lunes, puesto que desde el fin de la jornada del sábado hasta el inicio de la mañana del lunes han transcurrido solamente treinta y seis horas. En este sentido, debemos subrayar que ciertamente la referencia a un día y medio de descanso ha de interpretase pro operario, esto es, debe entenderse como la necesidad de descansar treinta y seis horas de manera ininterrumpida ${ }^{26}$.

Ya con anterioridad, se había señalado ${ }^{27}$ que cuando el día de descanso de un trabajador coincide con un domingo, el descanso semanal comprende igualmente la tarde del sábado o la mañana del lunes, y este descanso se acumula a las doce horas de descanso diario. Y si el día completo de descanso semanal se disfruta entre semana, el medio día de descanso se debe conceder la tarde del día previo o la mañana del día siguiente. Y si el día y medio de descanso semanal se tiene que fraccionar, el descanso se disfrutaría a razón de un día

${ }^{25}$ GARCía Ninet, José Ignacio, “Ordenación del tiempo de trabajo”, TS, núm. 43, 1994, p. 29.

${ }^{26}$ STS de 5 de octubre de 2010, rec. núm. 25/2009, que literalmente indica que "la interpretación efectuada del precepto controvertido no supone (....) que el tiempo libre correspondiente al día en que el trabajador ha realizado su jornada completa no pueda computarse como tiempo de descanso semanal, sino que lo que no cabe interpretar es que día y medio de descanso semanal supone únicamente 36 horas seguidas de descanso. Día y medio de descanso semanal, como claramente señala la sentencia de instancia... supone que si, al trabajador le coincide el día de descanso semanal en domingo, ha de descansar también la tarde del sábado o la mañana del lunes y, si no coincide en domingo, el descanso semanal incluirá el día correspondiente y la tarde del antecedente o mañana del siguiente". En el mismo sentido STS de 20 de diciembre de 2002, rec. núm. 148/2001; SSTSJ País Vasco, de 1 de junio de 2011, rec. núm. 805/2011; Madrid, de 14 de octubre de 2010, rec. núm. 506/2010; Canarias, de 29 de septiembre de 2006, rec. núm. 900/2005; Madrid, de 8 marzo de 1995; Galicia, de 10 de diciembre de 1999, rec. núm. 4833/1996; Murcia, de 24 de noviembre de 1994, rec. núm. 1074/1993.

${ }^{27}$ SAN de 6 de julio de 2004, st. núm. 64/2004. 
completo en una semana y dos días en la siguiente, sin merma del descanso diario de doce horas.

A mi parecer y el de parte de la doctrina científica ${ }^{28}$, no puede aplicarse el descanso semanal sin observar previa y necesariamente el descanso diario o entre jornadas, pues constituye un límite imperativo a la ordenación del tiempo de descanso de los trabajadores. De hecho, este conflicto se plantea respecto de los trabajadores con jornada partida y en aquellos casos en los que la jornada ordinaria de trabajo finaliza en momentos muy próximos al fin del día natural.

En realidad, el fondo de la cuestión se halla en la determinación del momento concreto en que debe concederse el medio día de descanso semanal. De entrada, conviene destacar que el legislador ordinario prevé que el día completo de descanso semanal será disfrutado, como regla general, el domingo, y a continuación, en relación con el medio día de asueto, se establece una opción, dado que el descanso se podrá disfrutar la tarde del sábado o la mañana del lunes. Dicha opción legislativa es un instrumento de ordenación del descanso semanal, en la medida que constituye una regla jurídica que permite determinar los días concretos en los que el derecho al descanso se va a disfrutar. Sin embargo, dicha ordenación previa de los días de descanso es una pauta meramente indicativa, debido a la posibilidad de alterar los días de disfrute del descanso en virtud de pactos individuales o colectivos. La determinación del medio día de descanso semanal, que se yuxtapone al día completo del domingo con el fin de conseguir las treinta y seis horas de descanso en cómputo semanal, es un aspecto que las partes pueden disponer en virtud de pacto colectivo o individual. Aunque el artículo 37.1 ET no diga nada al respecto, ésta parece la finalidad de la norma, ya que la referencia a estos días de la semana se prevé como regla general, pudiéndose contemplar otra opción en materia de fijación del descanso ${ }^{29}$. Por tanto, la determinación del medio día de descanso no es un criterio totalmente rígido, puesto que es posible introducir reglas de cómputo irregular del medio día de reposo en virtud de la acumulación del descanso en períodos de referencia de hasta catorce días. De hecho, según la doctrina judicial comunitaria ${ }^{30}$ no se puede imponer que se tenga que

\footnotetext{
${ }^{28}$ Asimismo, lo entiende LóPez AHUMADA, José Eduardo, "Problemas relativos al cómputo del descanso semanal y diario: una visión cualitativa del tiempo de descanso", AS, núm. 84, 2008 (versión on line)

${ }^{29}$ GARCíA NinET, José Ignacio, "Ordenación del tiempo de trabajo”, en AA.VV., Comentarios a las Leyes Laborales. El ET. Madrid, Edersa, 1994, p. 98; Alfonso Mellado, Carlos Luis; PeÑa Obiol, Salomé, Vacaciones, fiestas y descanso semanal. Valencia, Tirant lo Blanch, 1996, p. 69

${ }^{30}$ STJUE de 9 de noviembre de 2017, C-306/206, Asunto Maio. Literalmente indica que "por cada período de siete días no se refieren a un momento preciso en el que deba tener lugar el descanso semanal, sino que más bien aluden a una duración (siete días) dentro de la cual debe concederse tal período de descanso. Además, la redacción de esta disposición no hace mención alguna a "dias de trabajo consecutivos", sino que, al contrario, exige que se conceda el período de descanso semanal por cada período de siete días, con
} 
disfrutar el día de descanso forzosamente por cada seis días consecutivos de trabajo. Ello tiene especial importancia en actividades empresariales dedicadas al comercio con horario de apertura de casi todos los días del año, pues permitiría al empleado disfrutar de días de descanso consecutivos al final de un período de referencia o al comienzo del siguiente, así como organizar mejor los descansos de todo el personal al no establecerse la obligación de determinar días de descanso fijos.

En definitiva, en caso de solapamiento, no se puede producir la omisión del medio día de descanso semanal o bien la merma de determinadas horas correspondientes al descanso entre jornadas. El descanso semanal no acoge en su seno al descanso diario, de la misma forma que éste no acoge en el suyo a aquél, pues se trata de dos ciclos bien diferenciados, esto es, el ciclo de veinticuatro horas, equivalente a un día natural, dentro del cual se halla el período mínimo de descanso diario de doce horas consecutivas, y, por otro lado, el ciclo semanal, dentro del cual se instala el descanso de día y medio ${ }^{31}$. Así, aunque ambos tienen como objetivo común el limitar la distribución de la jornada laboral, sobre todo en los casos en los que ésta se distribuya irregularmente, y garantizar el descanso y la recuperación de la persona trabajadora, sin embargo, su incidencia es diferente. El descanso diario o entre jornadas actúa como límite intrínseco a la delimitación de la jornada laboral, tiene un carácter más intenso que el semanal, y responde a la necesidad biológica del ser humano de descansar, de tener un asueto u ocio, o simplemente de dedicarse a otras actividades, como las familiares, tras una jornada de trabajo, mientras que el descanso semanal tiene como fin introducir dentro de las jornadas sucesivas de trabajo un período de cesión o interrupción cíclica de las mismas cada cinco jornadas y media de trabajo.

Precisamente, el respeto de la finalidad del descanso supone no olvidar la periodicidad diaria del descanso, previsión normativa que tutela la salud laboral de los trabajadores, debiendo concederse el descanso "entre el final de una jornada y el comienzo de la siguiente" (artículo 34.3.1 ET). Estamos, pues, ante un límite legal a la jornada de trabajo que reside en el fundamento mismo del descanso ${ }^{32}$. El descanso entre jornadas se presenta en la regulación del tiempo de trabajo, en principio y a salvo de determinadas excepciones reglamentarias, como un tope legal de carácter absoluto en relación a cualquier sistema de ordenación del tiempo de trabajo. Las doce horas de reposo laboral se entienden aplicables a la jornada laboral continuada o a la partida, a las jornadas ordinarias o especiales, así como a los horarios de trabajo comunes o irregulares de carácter flexibles.

independencia de si el trabajador ha trabajado o no durante esos siete días y de la medida en que lo haya hecho".

${ }^{31}$ SAN de 7 de mayo de 2007, st. núm. 44/2007.

32 Alarcón CARACUEl, Manuel Ramón, La ordenación del tiempo de trabajo. Madrid, Tecnos, 1988, p. 90 . 
Se trata, en consecuencia, de un límite omnicomprensivo del desarrollo temporal de la prestación de servicios por cuenta ajena. Todo lo contrario sucede en materia de descanso semanal, cuyo disfrute se puede ordenar flexiblemente en relación a la ubicación del descanso en la semana, fraccionamiento del período de reposo o su cómputo semanal o bisemanal. Ciertamente, en este descanso las nuevas reglas de ordenación flexible del descanso han incidido directamente sobre el carácter necesario del derecho. Así, se puede apreciar cómo al margen de la duración del descanso, que siempre ha tenido el carácter de derecho mínimo, indisponible e inderogable para la voluntad colectiva o individual de las partes, las nuevas posibilidades de ordenación irregular del descanso permiten la disposición de los límites inherentes a la distribución de la interrupción semanal del trabajo.

Es más, nuestro alto tribunal supremo ${ }^{33}$ ha estimado procedente que el empresario compense a los trabajadores con una indemnización de daños y perjuicios el solapamiento causado entre dicho descanso, no sólo por no recuperarse del cansancio y esfuerzo que conlleva todo trabajo, sino también por no poder compatibilizar su vida laboral, familiar y personal.

\section{Concreción del día de disfrute}

\subsection{Aspectos generales}

El artículo 37.1 ET establece unos días concretos de la semana como días de disfrute del descanso semanal, concretamente, la tarde del sábado o la mañana del lunes y el domingo completo.

Esta previsión normativa es de carácter dispositivo para las partes ${ }^{34}$, por lo que se pueden fijar otros días distintos para el descanso ya sea vía convencional o contractual. Así lo indica también la doctrina jurisprudencial al estimar que la mención literal a la tarde del sábado o la mañana del lunes y el día completo del domingo no significa que no pueda establecerse el descanso en otros días de la semana ${ }^{35}$.

\footnotetext{
${ }^{33}$ SSTS (ambas) de 14 de abril de 2014, rec. núm. 1665/2013 y 1667/2013. En el mismo sentido, STSJ Madrid, de 14 de octubre de 2010, rec. núm. 506/2010.

34 Alfonso Mellado, Carlos Luis; PeÑa Obiol, Salomé, Vacaciones, fiestas y descanso semanal. Valencia, Tirant lo Blanch, 1996, p. 68.

35 STS de 23 de enero de 1991, rec. núm. 818/1990.
} 
En base a este carácter dispositivo ${ }^{36}$, se permite que, cuando por razones derivadas de la actividad empresarial, el descanso no pueda disfrutarse en domingo, se establecerá un día sustitutorio, como es el caso de trabajos que no admiten interrupción o trabajos ocasionados por circunstancias imprevisibles o perentorias que sea preciso atender, quedando en la actualidad reconducidos a dos supuestos, cuales son, los reglamentariamente contemplados en la norma preceptiva sobre jornadas especiales, y los que haya podido establecer el convenio colectivo, y en su defecto el pacto individual instrumentalizado en el contrato de trabajo. Así, el RD 1561/1995 sobre jornadas especiales contempla un amplio margen dentro de estas facultades legalmente atribuidas, pues se prevén numerosos supuestos de reducciones de los descansos entre jornadas y de descanso semanal, estableciendo que en tal caso deberán ser compensadas mediante descansos alternativos.

Se prevé también la posibilidad de acumular por períodos de cuatro semanas el medio día de descanso o separarlo del día completo para que sea disfrutado aisladamente con la ruptura del carácter ininterrumpido. Esta alternativa se ofrece para el trabajo a turnos (artículo 19 RD 1561/1995), para trabajos específicos como el de fincas urbanas (artículo 3.2 RD 1561/1995); el de guardas y vigilantes no ferroviarios (artículo 4.2 RD 1561/1995), los agrícolas, forestales y pecuarios (artículo 5.3 RD 1561/1995), los del sector comercio y la hostelería (artículo 6 RD 1561/1995), o los realizados en puestos de trabajo subterráneo donde puede acumularse el segundo día completo por períodos de hasta cuatro semanas o adicionarlo a otros descansos como las vacaciones. En otros, se permite que el cómputo del descanso semanal completo se compute por largos períodos como las cuatro semanas de los trabajos en el mar o los transportes por carretera (artículo 9 RD 1561/1995) o las ocho de los trabajos en condiciones de aislamiento o lejanía (artículo 21 RD 1561/1995).

Uno de los sectores en los que más cambios se está llevando a cabo es en el sector del comercio, pues, en los últimos años ha quedado patente que el período de mayor actividad comercial diaria se produce en viernes y fin de semana, siendo en la actualidad, especialmente, sábados y domingos, pues se ha producido una modificación de los hábitos de compra, y los meses en los que se desarrolla una mayor actividad comercial a lo largo del año son julio, diciembre y enero ${ }^{37}$. A ello se ha unido la situación de acentuada crisis

\footnotetext{
${ }^{36}$ SSTSJ Galicia, de 12 de abril de 2005, rec. núm. 1342/2005, que señala que "la significativa expresión "como regla general" nos permite concluir el carácter dispositivo en la determinación concreta del día y medio de descanso, de ahí la posibilidad de establecer otra determinación diferente a través de pacto colectivo o individual". En el mismo sentido, SSTSJ Navarra, de 17 de enero de 2005, rec. núm. 445/2004; Galicia, de 10 de diciembre de 1999, rec. núm. 4833/1996; Galicia, de 7 de julio de 2014, rec. núm. 2987/2012.

${ }^{37}$ SAN de 23 de noviembre de 2009, proc. núm. 227/2009; STSJ Madrid, de 14 de diciembre de 2012, rec. núm. 59/2012.
} 
económica producida en España que ha reducido el volumen de ventas, situación ante la cual, el sector comercial ha tomado medidas para aumentar sus beneficios, siendo una de ellas, la apertura en domingos y festivos. Además, en este sector es habitual que se finalice la jornada diaria en sábado o se comience la misma en lunes, así como que coincida la finalización de turnos en uno de dichos días señalados, elementos que plantean problemas de determinación del disfrute del descanso diario y su posible superposición con el descanso semanal. En este caso, lo lógico es que se debe disfrutar por cada semana un período mínimo de treinta y seis horas sin solaparse con el descanso diario ${ }^{38}$.

\subsection{Descanso semanal, domingo y religión católica}

En este sentido, se ha planteado si el hecho de establecer el domingo como día de descanso respondía o no a un aspecto religioso, estimando la doctrina constitucional ${ }^{39}$ que el descanso semanal es una institución secular y laboral y que la fijación del domingo como día de referencia para el disfrute de este descanso responde a razones de tradición, y que teniendo en cuenta nuestra sociedad actual los fines sociales de este derecho se cumplen cuando el descanso se disfruta de forma general en los mismos días por parte de la colectividad.

No cabe duda de que el establecimiento del domingo como período de descanso semanal tiene, en cierta forma, una conceptuación religiosa, pero sin que de ello pueda inferirse que la ley establezca un régimen favorable para unos creyentes y desfavorable para otros $^{40}$. Según el $\mathrm{TC}^{41}$, la libertad religiosa comporta, y en base al principio de igualdad, el tratamiento paritario de las distintas confesiones religiosas, pues "en España, como en los pueblos de civilización cristina, el domingo, obedece a que tal día es el que por mandato religioso y por tradición se ha acogido en estos pueblos" sin que este hecho "puede llevar a la creencia de que se trata del mantenimiento de una institución con origen causal único religioso". Por tanto, se ha estimado constitucionalmente irreprochable tanto por la tradición como por las costumbres, entendido en nuestra sociedad como "el tradicional y generalizado descanso" en cómputo semanal.

Según el TC, el artículo 3 LOLR $^{42}$ garantiza el ejercicio de los derechos dimanantes de la libertad religiosa y de culto al tiempo que señala que este ejercicio "tiene como único límite la protección del derecho de los demás al ejercicio de sus libertades públicas y

\footnotetext{
38 STSJ Canarias, de 29 de octubre de 2006.

${ }^{39}$ STC 19/1985, de 13 de febrero.

${ }^{40}$ NIETO ROJAS, Patricia, "Libertad religiosa y negociación colectiva. Su especial incidencia en la fijación de los descansos laborales", RIL, núm. 4, 2017 (versión on line)

${ }^{41}$ STC 19/1985, de 13 de febrero.

${ }^{42}$ LO 7/1980, de 7 de junio, de libertad religiosa.
} 
derechos fundamentales, así como la salvaguardia de la seguridad, de la salud y de la moralidad pública, elementos constitutivos del orden público protegido por la Ley en el ámbito de una sociedad democrática", pero si, como ocurre en el supuesto de hecho, existe una alegada incompatibilidad entre la práctica religiosa y el cumplimiento de las obligaciones laborales es, a juicio del TC, "evidente que el respeto a los derechos fundamentales y libertades públicas garantizados por la Constitución es un componente esencial del orden público, y que, en consecuencia, han de tenerse por nulas las estipulaciones contractuales incompatibles con este respeto", sin que, en modo alguno, "la invocación de estos derechos o libertades puede ser utilizada por una de las partes contratantes para imponer a la otra las modificaciones de la relación contractual que considere oportunas".

A pesar de las críticas de esta postura que mantuvo el TC, la doctrina coincide en que con dicha decisión el TC renunció a buscar una adecuación entre el ejercicio fundamental de la libertad religiosa y la organización del trabajo al no realizar "ningún intento de establecer una mínima obligación por parte del empresario de poder acomodar el ejercicio en buena fe de los derechos fundamentales de sus trabajadores y la organización del trabajo" ${ }^{43}$.

Posiblemente, esta regulación es deudora de un determinado contexto histórico en el momento de redacción del ET, concretamente, del marco de colaboración entre la Santa sede y el Gobierno Español que sentó las bases para la articulación de la relación entre el Estado español y la Iglesia Católica, pues, en dicho Acuerdo ${ }^{44}$ el Estado español reconoce como días festivos todos los domingos.

El artículo 7 LOLR prevé que "el Estado, teniendo en cuenta las creencias religiosas existentes en la sociedad española, establecerá, en su caso, Acuerdos o Convenios de cooperación con las Iglesias, Confesiones y Comunidades religiosas inscritas en el Registro que, por su ámbito y número de creyentes, hayan alcanzado notorio arraigo en España", habiéndose procedido a este reconocimiento con tres confesiones religiosas con las que suscribieron los correspondientes acuerdos ${ }^{45}$. En dichos acuerdos se establecen

\footnotetext{
${ }^{43}$ García-Perrote Escartín, Ignacio; Mercader Uguina, Jesús, "Conflicto y ponderación de los derechos fundamentales de contenido laboral: un estudio introductorio", en Sempere Navarro, Antonio Vicente, (Coord.) El modelo social en la Constitución Española de 1978. Madrid, Ministerio de Trabajo y Asuntos Sociales, 2003, p. 272.

${ }^{44}$ De 28 de julio de 1976, Instrumento de Ratificación del Acuerdo entre el Estado Español y la Santa Sede sobre asuntos jurídicos.

${ }^{45}$ Ley 24/1992, con la que ratifica el Acuerdo de Cooperación del Estado Español con la federación de Entidades Religiosas Evangélicas de España; Ley 25/1992, por la que se aprueba el Acuerdo de Cooperación del Estado Español con la Federación de Comunidades Israelitas de España; Ley 26/1992, por la que se aprueba el acuerdo de Cooperación del Estado Español con la Comisión Islámica de España.
} 
las previsiones para poder cambiar el día de disfrute del descanso semanal, siempre que exista acuerdo entre las partes.

Como se observa, se trata de una cuestión de conciliación de las prácticas religiosas de las personas trabajadoras de otras confesiones diferentes a la católica con las necesidades organizativas de la empresa, debiéndose aplicar como pauta interpretativa la doctrina constitucional que indica que "dicho trato no debe entenderse como uniformidad, sino como proporcionalidad cualitativa lo que supone no la existencia de un tratamiento legal igual, con abstracción de cualquier elemento diferenciador de relevancia jurídica, sino en función de las circunstancias que concurran en cada supuesto concreto en relación con el cual se invoca" ${ }^{46}$. No obstante, esta interpretación no ha sido asumida en relación a los descansos semanales, sino que el TC optó por la tesis más restrictiva al impedir disfrutar el período distinto al domingo si no media acuerdo colectivo o si no se logra la aquiescencia entre trabajador y empresario.

Por ello, un sector doctrinal ${ }^{47}$ considera que, si existen las condiciones para el reconocimiento a un trabajador del día de descanso semanal acostumbrado por su religión, la empresa debería conceder el descanso, salvo que acredite el perjuicio cierto que supone esa alteración, pues es obvio que las leyes que contemplan el acomodo del descanso semanal al día tradicionalmente acostumbrado por las confesiones religiosas diferentes a la católica no deberían interpretar como mandatos inocuos en las relaciones laborales sino que esta regulación debería vincular de algún modo a los sujetos de las relaciones laborales, incluso aunque no exista acuerdo entre empresa y persona trabajadora.

Este régimen de determinación de festivos, como se observa, queda condicionado a la necesidad del acuerdo y se ha justificado en base "al peso histórico y sociológico que la Iglesia Católica tiene en nuestro país, lo que ha originado que parte del calendario laboral oficial sea determinado de acuerdo con esta Iglesia"48.

\subsection{Descanso semanal, domingo y conciliación de la vida laboral y familiar}

Los problemas de conciliación de trabajo y familia, desde una perspectiva estrictamente jurídico-laboral, derivan con carácter general del tiempo en que el trabajador, por estar en

\footnotetext{
${ }^{46}$ Contreras Mazarío, José María, Marco jurídico del factor religioso en España. Madrid, Observatorio del Pluralista Religioso en España, 2011, p. 18. Disponible en http://www.observatorioreligion.es/upload/83/51/Marco_juridico.pdf

${ }^{47}$ NIETO RoJAS, Patricia, "Libertad religiosa y negociación colectiva. Su especial incidencia en la fijación de los descansos laborales", RIL, núm. 4, 2017 (versión on line)

${ }^{48}$ López AhumadA, José Eduardo, Descansos laborales y tiempo de trabajo. Régimen jurídico de los descansos diario y semanal y de los días festivos. Madrid, CES, 2004, p. 283.
} 
su puesto de trabajo, no puede atender a las necesidades derivadas de sus circunstancias familiares.

En el ámbito laboral, con anterioridad a la Ley 31/199949, el ET no contemplaba medidas de ordenación y racionalización del tiempo de trabajo desde el punto de vista de los intereses de los trabajadores, ya que únicamente reflejaba posibles medidas de flexibilidad del tiempo de trabajo desde la perspectiva de la empresa. Con la citada ley se dio un paso importante en la adopción de mejoras en la protección social y el desarrollo de prestaciones económicas, reordenando la regulación de situaciones de maternidad y riesgo, si bien dejó bastante limitado el objetivo de avanzar en la corresponsabilidad de hombres y mujeres. Posteriormente, con la LO $3 / 2007^{50}$ se intenta hacer efectivo el derecho de igualdad de trato en cualquier ámbito de la vida y entre ellos el laboral, pues en su exposición de motivos se fija como un criterio regulador de la actuación de los poderes públicos el fomento de la corresponsabilidad en las labores domésticas y en la atención a la familia, así como la reorganización del tiempo de trabajo con la finalidad de mejorar la posibilidad de conciliación de la vida laboral y personal de los trabajadores.

Por último, es con el RDL 6/2019 ${ }^{51}$ cuando se lleva a cabo una importante modificación normativa en aras de favorecer y garantizar una efectiva conciliación de la vida laboral y familiar y promover la corresponsabilidad entre ambos sexos, modificando asimismo el citado artículo 34.8 ET que establece "las personas trabajadoras tienen derecho a solicitar las adaptaciones de la duración y distribución de la jornada de trabajo, en la ordenación del tiempo de trabajo y en la forma de prestación, incluida la prestación de su trabajo a distancia, para hacer efectivo su derecho a la conciliación de la vida familiar y laboral. Dichas adaptaciones deberán ser razonables y proporcionadas en relación con las necesidades de la persona trabajadora y con las necesidades organizativas o productivas de la empresa. En el caso de que tengan hijos o hijas, las personas trabajadoras tienen derecho a efectuar dicha solicitud hasta que los hijos o hijas cumplan doce años. En la negociación colectiva se pactarán los términos de su ejercicio, que se acomodarán a criterios y sistemas que garanticen la ausencia de discriminación, tanto directa como indirecta, entre personas trabajadoras de uno y otro sexo. En su ausencia, la empresa, ante la solicitud de adaptación de jornada, abrirá un proceso de negociación con la persona trabajadora durante un periodo máximo de treinta días. Finalizado el mismo, la empresa, por escrito, comunicará la aceptación de la petición, planteará una propuesta alternativa que posibilite las necesidades de conciliación de la persona

\footnotetext{
${ }^{49}$ De 5 de noviembre, para promover la conciliación de la vida familiar y laboral de las personas trabajadoras.

${ }^{50}$ De 22 de marzo, para la igualdad efectiva de mujeres y hombres.

${ }^{51}$ De 1 de marzo, de medidas urgentes para garantía de la igualdad de trato y de oportunidades entre mujeres y hombres en el empleo y la ocupación.
} 
trabajadora o bien manifestará la negativa a su ejercicio. En este último caso, se indicarán las razones objetivas en las que se sustenta la decisión". Con ello, se trata de facilitar que se garantice una efectiva conciliación de la vida laboral y familiar promoviendo la adaptación del horario de trabajo, la distribución de la jornada de trabajo o la duración de la misma a las necesidades familiares de la persona trabajadora.

No cabe duda de que, esta previsión es compleja en diversas actividades, especialmente el sector comercial, pues, según lo indicado y a la vista de los actuales hábitos de compra, no resulta nada acorde con las necesidades organizativas de las empresas.

Desde la experiencia convencional, la negociación colectiva, sobre todo la de nivel de empresa, ha sido el instrumento para gestionar esa progresiva flexibilización en la ordenación del tiempo de trabajo a favor del interés empresarial. No obstante, esa generalización no ha sido secundada con carácter general por los trabajadores. De hecho, la flexibilización en interés del trabajador, en la actualidad, no se vincula al reparto de empleo, esto es, la reducción del tiempo de trabajo como medida de política de empleo, sino con la conciliación de la vida laboral, familiar y personal. Además, la utilización de la negociación colectiva como instrumento de conciliación constituye una pauta común en varios países europeos ${ }^{52}$.

En definitiva, satisfacer las necesidades conciliatorias requiere una labor de diálogo y negociación entre representantes de los trabajadores, empresarios y los propios trabajadores. Cabe tener en cuenta que no sólo la organización empresarial y productiva tienen peculiaridades que deben marcar esa negociación en la materia sino también la plantilla de trabajadores presentará características propias que hagan que no todas las medidas conciliatorias satisfagan realmente sus intereses de conciliación familiar, laboral y personal, y son dichas características propias las que deben estar presentes en los interlocutores sociales a la hora de negociar las mismas, pues, en caso contrario, de nada servirían medidas conciliatorias previstas en el convenio colectivo que para nada responden a las necesidades conciliatorias de los incluidos en su ámbito personal de aplicación. Sólo con un diálogo fluido y continuo entre todas las partes implicadas, podrá lograrse que, velar por los intereses conciliatorios, se convierta en un objetivo intrínseco y permanente a la relación laboral que se concreta en la realización de una prestación de servicios.

Parte de la doctrina judicial ${ }^{53}$ ha señalado que la conciliación de la vida familiar y laboral debe ser un principio rector de la regulación y de la negociación colectiva, pero del mismo

\footnotetext{
${ }^{52}$ PÉREZ DEL Río, Teresa, “Tiempo de trabajo: una óptica de género”, en AA.VV., Tiempo de trabajo, Albacete, Bomarzo, 2007, p. 273.

${ }^{53}$ SAN de 19 de noviembre de 2013, rec. núm. 290/2013.
} 
debe tenerse presente que los trabajadores no tienen un derecho expresamente reconocido a que los horarios de la empresa se ajusten a sus necesidades laborales, sino que dependerá de lo que se pacte.

De cualquier modo, debe citarse un pronunciamiento de nuestro alto tribunal (aunque de la sala de lo contencioso-administrativo) ${ }^{54}$ en el que se avala el sistema de descanso obligatorio de un día fijo a la semana fijado en la ordenanza municipal reguladora del taxi de Madrid, puesto que considera que ello entra dentro de las facultades de organización de la corporación municipal al no existir una norma de rango superior que establezca un criterio específico que deba ser seguido. Entre los diferentes motivos alegados, se argumenta que el establecimiento de un día fijo de descanso semanal permite una adecuada conciliación de la vida familiar y laboral, ya que permite controlar el día de libranza y permite que cualquier comprador de una licencia sepa desde el primer momento cuál es el día de libranza que tiene asignado. Concretamente, indica que este método "favorece la conciliación familiar y social, pues da seguridad jurídica a quienes adquieren una licencia de taxi pues el conocimiento previo de su régimen de descanso aplicable les permite organizar la vida privada, siendo que en más de un $60 \%$ de los titulares de licencia son autónomos que conducen su propio taxi sin conductores aislados".

\section{Acumulación del descanso semanal por períodos de hasta catorce días}

\subsection{La ordenación del descanso semanal según la norma estatutaria}

El artículo 37.1 ET regula la posibilidad de acumular el disfrute del descanso semanal por períodos de hasta catorce días, previsión acorde con el artículo 16 Directiva 2003/88/CE, que fija el período máximo de acumulación del descanso semanal en también catorce días. De esta forma, el artículo 37.1 ET posibilita un ciclo de trabajo consistente en prestar servicios durante once días consecutivos y descansar tres, a los que se sumaría el descanso diario, según lo indicado anteriormente sobre acumulación de descanso diario y semanal. Según un sector doctrinal ${ }^{55}$, esta previsión pone en entredicho "la esencia semanal del descanso".

\footnotetext{
${ }^{54}$ STS, Sala de lo contencioso-administrativo, de 5 de junio de 2020, rec. núm. 5571/2017.

${ }^{55}$ CABEZA Pereiro, Jaime, "Descanso semanal, fiestas, permisos y reducción de jornada por lactancia y guardia legal (En torno al artículo 37)”, REDT, núm. 100, 2000, p. 784.
} 
De cualquier forma, debe destacarse que esta previsión estatutaria no es acorde con los Convenios de la $\mathrm{OIT}^{56}$, pues los artículos 2.1 Convenio núm. 14 OIT, y 6.1 Convenio núm. 106 OIT, establecen que los trabajadores deben disfrutar de un período de descanso de, al menos, 24 horas por cada período de siete días. De hecho, la Comisión de Expertos en Aplicación de Convenios y Recomendaciones de la OIT ha realizado algunos requerimientos al Gobierno de España para que adopte las medidas necesarias para adaptar la legislación a las disposiciones de los Convenios OIT ${ }^{57}$. Concretamente, ha señalado que "desde hace varios años, la Comisión ha llamado la atención del Gobierno sobre lo dispuesto en el artículo 37, párrafo 1, del Estatuto de los Trabajadores, donde se prevé la posibilidad de un descanso semanal acumulable por períodos de 14 días, un precepto que va más allá de lo autorizado por el artículo 6, párrafo 1, del Convenio, que exige un período de descanso semanal ininterrumpido de 24 horas en el curso de cada período de siete días. A este respecto, la Unión General de Trabajadores (UGT) había subrayado, en sus comentarios anteriores, el hecho de que esta disposición podría redundar negativamente sobre la salud y la seguridad de los trabajadores, así como la calidad de los trabajos efectuados. En su memoria, el Gobierno indica que la legislación nacional en su conjunto aplica las disposiciones del Convenio y que las excepciones al régimen general no pueden imponerse de manera unilateral por el empleador, sino que son negociados con los representantes de los trabajadores. El Gobierno añade que la legislación es plenamente conforme con las disposiciones de la directiva núm. 2003/88/CE del Parlamento europeo y del Consejo relativa a determinados aspectos de la ordenación del tiempo de trabajo y, en particular, con el artículo 16, a), que establece que los Estados Miembros podrán establecer un período de referencia que no exceda de 14 días para establecer un descanso semanal. Tomando nota de las explicaciones del Gobierno, la Comisión recuerda que el artículo 37, párrafo 1, del Estatuto de los Trabajadores es contraria a las disposiciones del Convenio. La Comisión espera, por consiguiente, que el Gobierno tendrá a bien revisar esta cuestión para adoptar, en un futuro próximo, las medidas necesarias para poner su legislación en plena conformidad con las disposiciones del Convenio" $"$.

Este conflicto debe ser resuelto a favor de las normas internacionales, pues así se deduce del artículo 351 TFUE que señala que "las disposiciones de los Tratados no afectarán a los derechos y obligaciones que resulten de convenios celebrados con anterioridad al 1

\footnotetext{
${ }^{56}$ CAMPs RuIZ, Luis Miguel, "Los Convenios de la OIT sobre vacaciones y sobre descanso semanal", RMTSS, núm. 112, 2014, p. 29.

${ }^{57}$ Informe de la $98^{\text {a }}$ Reunión de la Conferencia Internacional de Trabajo, de 2009. Disponible en https://www.ilo.org/wcmsp5/groups/public/@ed_norm/@relconf/documents/meetingdocument/wcms_10 3488.pdf

${ }^{58}$ Informe de la $98^{\mathrm{a}}$ Reunión de la Conferencia Internacional de Trabajo, de 2009. Disponible en https://www.ilo.org/wcmsp5/groups/public/@ed_norm/@ @elconf/documents/meetingdocument/wcms_10 3488.pdf
} 
de enero de 1958 o, para los Estados que se hayan adherido, con anterioridad a la fecha de su adhesión, entre uno o varios Estados miembros, por una parte, y uno o varios terceros Estados, por otra".

No obstante, debe tenerse en cuenta la actual interpretación realizada por la doctrina comunitaria en relación con los artículos 5 y 16 Directiva 2003/88/CE. Así, el artículo 5 Directiva 2003/88/CE establece que "los Estados miembros adoptarán las medidas necesarias para que todos los trabajadores disfruten, por cada período de 7 días, de un período mínimo de descanso ininterrumpido de 24 horas, a las que se añadirán las 11 horas de descanso diario" y el artículo 16 a) Directiva 2003/88/CE señala que "los Estados miembros podrán establecer un período de referencia más largo para la aplicación del artículo 5 de dicha Directiva, relativo al descanso semanal".

El TJUE ${ }^{59}$ ha considerado que "por cada período de 7 días" debe entenderse como un término independiente y autónomo y que debe interpretarse de manera uniforme. El TJUE estima que el precepto comunitario establece la obligación de que los trabajadores disfruten por cada período de 7 días, de un período mínimo de descanso, pero no precisa el momento en que debe disfrutarse del mismo, permitiendo así un cierto grado de flexibilidad a la hora de determinar el momento de su disfrute. De esta forma, el artículo 16 Directiva señala que los Estados miembros pueden establecer un período de referencia que no exceda de 14 días para la aplicación del citado artículo 5. No obstante, aunque no recibe expresamente esta denominación, el período de 7 días puede también considerarse como un período de referencia, esto es, entenderlo como el período dentro del cual deben concederse un determinado número de horas de descanso consecutivas con independencia del momento en que se concedan efectivamente.

En definitiva, el TJUE concluye que "el artículo 5, párrafo primero, de la Directiva 2003/88 debe interpretarse en el sentido de que no exige que el período mínimo de descanso semanal ininterrumpido de 24 horas al que tiene derecho todo trabajador sea concedido a más tardar el día siguiente a un período de seis días de trabajo consecutivos, pero sí que impone que sea concedido dentro de cada período de siete días".

\subsection{La ordenación del descanso semanal en la negociación colectiva}

Por mandato del legislador, la negociación colectiva se convierte en instrumento imprescindible de organización del tiempo de trabajo. Así, el artículo 34.1 ET indica que "la duración de la jornada de trabajo será la pactada en los convenios colectivos o

\footnotetext{
${ }^{59}$ STJUE de 9 de noviembre de 2017, C-306/206, Asunto Maio.
} 
contratos de trabajo", siendo éstos los que pueden fijar su distribución irregular, así como que el descanso semanal pueda acumularse en períodos de hasta catorce días. El legislador remite de este modo para la ordenación del tiempo de trabajo a la negociación colectiva, otorgando todo el protagonismo en la cuestión a los convenios colectivos y a los contratos de trabajo, que deberán tomar el testigo dado por el legislador para conseguir que el tiempo de trabajo no suponga un obstáculo a la conciliación de la vida familiar y laboral.

Además, con las últimas reformas laborales se ha visto reforzado el papel de la negociación colectiva, y ello no ha pasado desapercibido para los negociadores, pues han acordado modificaciones relevantes que han afectado a la distribución irregular de la jornada de trabajo y, más aun teniendo presente la preferencia aplicativa del convenio de empresa frente al de sector en cuanto al horario y la distribución del tiempo de trabajo. Todo ello sitúa al convenio colectivo de empresa en un lugar destacado en la ordenación del tiempo de trabajo.

Si se observa la negociación colectiva al respecto, se confirma que algunos convenios ${ }^{60}$ reconocen la totalidad de la distribución irregular de la jornada de trabajo efectuada de conformidad con los cuadrantes horarios elaborados por la empresa, previendo incluso posibles modificaciones del mismo y limitando la comunicación a períodos inferiores a los señalados en el ET. Otros ${ }^{61}$ reconocen dicha distribución con tal generalidad que se ofrece como un arma en manos del empresario al no hacer concreción alguna en el convenio sino remitiendo a otras instancias. Incluso algunos convenios ${ }^{62}$ reconocen dicha posibilidad, en aras de la competitividad de la empresa sin hacer alusión tampoco alguna a los posibles problemas conciliatorios que en determinadas ocasiones la exigencia de esa bolsa de horas pueda suponer.

\footnotetext{
${ }^{60}$ VII Convenio colectivo del sector de derivados del cemento, Resol. de 30 de mayo de 2019; VIII Convenio colectivo estatal de gestorías administrativas, Resol. de 23 de noviembre de 2019; Convenio colectivo general de trabajo de la industria textil y de la confección, Resol. de 12 de marzo de 2020; Convenio colectivo para la industria azucarera, Resol. de 18 de diciembre de 2018; XXII Convenio colectivo nacional de autoescuelas, Resol. de 24 de septiembre de 2013; Convenio colectivo estatal de estaciones de servicio, Resol. de 2 de marzo de 2020; Convenio colectivo estatal de elaboradores de productos cocinados para su venta a domicilio, Resol. de 5 de diciembre de 2016; Convenio colectivo estatal de naturopatía y profesionales naturópatas, Resol. de 7 de mayo de 2018; Convenio colectivo estatal del sector de desinfección, desinsectación y desratización, Resol. de 23 de marzo de 2018.

${ }^{61}$ Convenio colectivo estatal de prensa diaria, Resol. de 19 de agosto de 2019; Convenio colectivo estatal de pastas, papel y cartón, Resol. de 27 de junio de 2019; Convenio colectivo estatal de jardinería, Resol. de 25 de enero de 2018.

${ }^{62} \mathrm{~V}$ Convenio colectivo de cadenas de tiendas de conveniencia, Resol. de 22 de junio de 2017; III Convenio colectivo de empresas de centros de jardinería, Resol. de 6 de julio de 2018; Convenio colectivo estatal de artes gráficas, manipulados de papel, manipulados de cartón, editoriales e industrias auxiliares, Resol. de 13 de febrero de 2020.
} 
El importante papel asignado a la negociación colectiva en materia de no discriminación sexista y de derechos de conciliación contrasta, sin embargo, con una trascendencia real que ha sido puesta en entredicho por toda la doctrina científica ${ }^{63}$ que ha analizado nuestra práctica negocial, pues en cuanto a las cuestiones de jornada, horario y, en general, tiempo de trabajo, se pone encima de la mesa que aunque la negociación colectiva introduce contenidos diversos, y cláusulas de indudable interés para la conciliación de la vida personal, familiar y laboral, en términos generales no puede decirse que los convenios hayan tenido demasiado en cuenta, salvo raras excepciones, esta perspectiva. De este modo, lo que hay son cláusulas aisladas que incorporan buenas prácticas y que pueden servir de modelos para su acogimiento en otras unidades de negociación. Falta, en consecuencia, una perspectiva general a favor de la conciliación y de la corresponsabilidad que sirva como idea inspiradora de la regulación.

Resulta así que muchas de las reglas no obedecen en su génesis a objetivos explícitos o implícitos de hacer más compatible el trabajo con las tareas extralaborales de las personas, si bien como generan ciertas garantías tales como predeterminación del tiempo de trabajo, fijeza en los descansos semanales o mayor duración de los mismos, adaptación de las vacaciones a las preferencias individuales o acumulación de los períodos de descanso, producen consecuencias positivas a la vez en la atención a la vida personal y familiar de trabajadores y trabajadoras. Por ello, se afirma que una negociación colectiva más inclinada a conseguir dichos objetivos, sin duda, puede todavía perfeccionar estas herramientas.

\section{Bibliografía}

Alarcón CARACUel, Manuel Ramón, La ordenación del tiempo de trabajo. Madrid: Tecnos, 1988.

Alfonso Mellado, Carlos Luis; Peña Obiol, Salomé, Vacaciones, fiestas y descanso semanal. Valencia, Tirant lo Blanch, 1996.

Alonso Olea, Manuel; Casas Baamonde, $\mathbf{M}^{\mathrm{a}}$ Emilia, Derecho del Trabajo. Madrid, Civitas, 2001.

BASTERra HernándeZ, Miguel, Tiempo de trabajo y tiempo de descanso. Valencia, Tirant lo Blanch, 2017 (versión on line)

\footnotetext{
${ }^{63}$ CABeZA Pereiro, Jaime, "Los derechos de conciliación de la vida personal, familiar y laboral de las personas trabajadoras", en AA.VV., El principio de igualdad en la negociación colectiva. Madrid, CCNCC, 2008.
} 
CABeZA PereIRO, Jaime, "Descanso semanal, fiestas, permisos y reducción de jornada por lactancia y guardia legal (En torno al artículo 37)”, REDT, núm. 100, 2000.

CABeza Pereiro, Jaime, "Los derechos de conciliación de la vida personal, familiar y laboral de las personas trabajadoras", en AA.VV., El principio de igualdad en la negociación colectiva. Madrid, CCNCC, 2008.

CAMPs RuIZ, Luis Miguel, "Los Convenios de la OIT sobre vacaciones y sobre descanso semanal”, RMTSS, núm. 112, 2014.

CAVAs Martínez, Faustino; LujÁn AlCARAZ, Juan, Buenas prácticas en la negociación colectiva: promoción de la igualdad de género y conciliación de la vida familiar y laboral". Murcia, Consejo Económico y Social de la Región de Murcia, 2008.

Contreras Mazarío, José María, Marco jurídico del factor religioso en España. Madrid, Observatorio del Pluralista Religioso en España, 2011. Disponible en http://www.observatorioreligion.es/upload/83/51/Marco_juridico.pdf

GARcía Ninet, José Ignacio, "Ordenación del tiempo de trabajo", en AA.VV., Comentarios a las Leyes Laborales. El ET. Madrid, Edersa, 1994

García NinET, José Ignacio, “Ordenación del tiempo de trabajo”, TS, núm. 43, 1994.

García-Perrote Escartín, Ignacio; Mercader Uguina, Jesús, "Conflicto y ponderación de los derechos fundamentales de contenido laboral: un estudio introductorio", en SEMPERE NAVARRO, Antonio Vicente, (Coord.) El modelo social en la Constitución Española de 1978. Madrid, Ministerio de Trabajo y Asuntos Sociales, 2003.

LAHERA FORTEZA, Jesús, Elección de descansos y vacaciones por preferencias de conciliación familiar. Madrid, Observatorio de recursos humanos y relaciones laborales, 2014.

LÓPEZ AHUMADA, José Eduardo, "Problemas relativos al cómputo del descanso semanal y diario: una visión cualitativa del tiempo de descanso", AS, núm. 84, 2008 (versión on line)

LóPez Ahumada, José Eduardo, Descansos laborales y tiempo de trabajo. Régimen jurídico de los descansos diario y semanal y de los días festivos. Madrid, CES, 2004. 
Molero Manglano, Carlos, (Coord.), Manual de Derecho del Trabajo. Valencia, Tirant lo Blanch, 2015 (versión on line)

NIETO RoJAS, Patricia, "Libertad religiosa y negociación colectiva. Su especial incidencia en la fijación de los descansos laborales”, RIL, núm. 4, 2017 (versión on line)

PÉREZ DEL Río, Teresa, “Tiempo de trabajo: una óptica de género”, en AA.VV., Tiempo de trabajo. Albacete, Bomarzo, 2007.

RAMOs QuinTANA, Margarita Isabel, "Los descansos laborales”, en AA.VV., Tiempo de trabajo. Albacete, Bomarzo, 2007. 